\title{
Lot-sizing for inventory systems with product recovery
}

\author{
Ruud Teunter*
}

August 29, 2003

\section{Econometric Institute Report EI2003-28}

\begin{abstract}
We study inventory systems with product recovery. Recovered items are as-good-as-new and satisfy the same demands as new items. The demand rate and return fraction are deterministic. The relevant costs are those for ordering recovery lots, for ordering production lots, for holding recoverable items in stock, and for holding new/recovered items in stock. We derive simple formulae that determine the optimal lot-sizes for the production/procurement of new items and for the recovery of returned items. These formulae are valid for finite and infinite production rates as well as finite and infinite recovery rates, and therefore more general than those in the literature. Moreover, the method of derivation is easy and insightful.
\end{abstract}

Key words: Product returns, recovery, lot sizing, EOQ/EPQ.

\footnotetext{
${ }^{*}$ Erasmus University Rotterdam, Econometric Institute, PO Box 1738, 3000 DR Rotterdam, The Netherlands. E-mail: teunter@few.eur.nl
} 


\section{Introduction}

Product recovery (repair, refurbishing, remanufacturing) is receiving increasing attention. In the past, engagement in recovery activities was often driven by legislation or by the associated environmentally friendly image. But nowadays, the main reason for companies to become involved with product recovery is economical. Being active in product recovery reduces the need for virgin materials and thus leads to reduced costs.

Our attention is focused on Original Equipment Manufacturers (OEM's) that are involved with product recovery. These differ from specialized recovery companies in that they also produce/procure new items. Moreover, we assume that recovered items are as-good-as-new and sold on the same market as new items. See Figure 1.

\section{INSERT FIGURE 1 ABOUT HERE}

We address the problem of determining optimal lot-sizes for production/procurement and recovery. This problem was first studied by Schrady (1967). He analyzes the problem in the traditional Economic Order Quantity (EOQ) setting: deterministic and continuous demand and return, infinite production and recovery rates. The objective is to minimize the total cost per time unit for placing orders and for holding inventory (different holding cost rates for recoverable items and serviceable items). He considers policies that alternate 1 production lot with a fixed number $R$ of recovery lots $((1, R)$ policies for short), and derives a pair of simple EOQ formulae.

Mabini, Pintelon \& Gelders (1992) discuss an extension of Schrady's model to a multi-item case.

Teunter (2001) generalizes the EOQ formulae for $(1, R)$ policies from Schrady (1967) by including a disposal option for non-serviceable items, and by using different holding cost rates for produced and recovered serviceable items. Furthermore, he also derives EOQ formulae for policies that alternate a fixed number $P$ of production lots and 1 recovery lot $((P, 1)$ policies for short).

Richter (1996a,1996b) also includes a disposal option (though a sub-optimal constant disposal rate is required) and studies both $(1, R)$ and $(P, 1)$ policies. However, his model differs from that of Schrady (1967) and Teunter (2001) in the existence of a collection point, where used items are collected and from there returned in batches. Richter derives a formula for the total average cost, but simple formulae for the optimal lot sizes are not obtained.

Nahmias \& Rivera (1979) study an EPQ variant of Schrady's model with a finite recovery rate. The production rate is still infinite. They assume that the recovery rate is larger than the demand rate, and derive lot-sizing formulae for $(1, R)$ policies.

Koh, Hwang, Sohn \& Ko (2002) also assume that the production rate is infinite and that the recovery rate is finite. Their study is more general that that of Nahmias \& Rivera (1979), since they allow the recovery rate to be both smaller and larger than the demand rate, and they consider both $(P, 1)$ and $(1, R)$ policies. For all 4 combinations, they derive a closed-form expression for the average total cost which can be used to determine the optimal lot-sizes numerically. We remark that the $(1, R)$ policies proposed by Koh et al. (2002) differ from those proposed by Nahmias \& Rivera (1979) (which are generalizations of Schrady's policies) in the timing of the recovery lots. As is explained in the appendix, the $(1, R)$ policies in Nahmias \& Rivera (1979) are better if the holding cost rate for serviceable items is larger than that for recoverable items, which is usually the case since recovery adds value to an item. 
To summarize the above mentioned findings, lot-sizing formulae have been derived for both $(P, 1)$ and $(1, R)$ policies, for infinite and finite recovery rates, but only for infinite production rates. In this paper, we derive more general lot-sizing formulae for both policies. (The $(1, R)$ policies are generalizations from those in Nahmias \& Rivera (1979).) These formulae are also valid for finite production rates. Furthermore, the formulae are derived in an insightful graphical way, avoiding the tedious calculations in previous work.

The remainder of this paper is organized as follows. The model and the assumptions are described, and notations are introduced in Section 2. Lot-sizing formulae for $(P, 1)$ and $(1, R)$ policies are derived in Sections 3 and 4, respectively. Their use is illustrated in Section 5 . We end with conclusions and discuss limitations in Section 6.

\section{Model and notation}

The planning horizon is infinite and time is continuous. Demand and return are continuous and deterministic. The demand rate is $d, d>0$. The return rate is $f d$, where $0<f<1$ is the return fraction. The production rate $p$ and recovery rate $r$ can be finite as well as infinite $(p, r \leq \infty)$. It is assumed that the production rate and the recovery rate are always larger than the demand rate. Realizing that companies often produce/recover many different items, this seems to be more realistic than to assume that the finite production/recovery rate for a specific item is smaller than its demand rate. We further assume that all returned items are recovered. Results by Teunter (2001) and Teunter \& Vlachos (2002) show that including a disposal option for recoverable items seldom leads to a considerable cost reduction.

Relevant costs are: the production ordering cost $K_{p}$ (per lot), the recovery ordering cost $K_{r}$ (per lot), the holding cost for recoverable items $h_{r}$ (per item per time unit), and the holding cost for serviceable items $h_{s}$ (per item per time unit). The objective is to find the lot-sizing policy that minimizes the average total cost per time unit. We do not consider all possible policies, but restrict our attention to two classes with a simple structure. The $(1, R)$ policies alternate 1 production lot with a fixed number $R$ of recovery lots (in a 'cycle'). The $(P, 1)$ policies alternate a fixed number $P$ production lots with 1 recovery lot. Both types of policies use fixed lot-sizes $Q_{p}$ for production and $Q_{r}$ for recovery.

These two classes of policies were also analyzed by previous authors (see Section 1). Neither we nor them claim that the optimal policy is always contained in these classes. The optimal policy might vary the number of lots in a cycle and the lot-sizes. However, such a complex policy will be difficult to apply in practice. Furthermore, as argued by Teunter $(2001)$, there is always a near-optimal $(1, R)$ or $(P, 1)$ policy.

So we restrict our attention to policies in the two classes $(1, R)$ or $(P, 1)$. In Section $3,(1, R)$ policies are considered. An expression for the total cost $T C^{(1, R)}\left(Q_{p}, Q_{r}\right)$ is derived. Ignoring the discreteness of $R$, simple formulae are derived for the optimal lot sizes $Q_{p}^{(1, R)}$ for production and $Q_{r}^{(1, R)}$ for recovery. Furthermore, a modified formulae $\widetilde{Q}_{p}^{(1, R)}$ for production is proposed, which ensures that $R$ is discrete. In Section 4, $(P, 1)$ policies are considered. An expression for the total cost $T C^{(P, 1)}\left(Q_{p}, Q_{r}\right)$ is derived. Ignoring the discreteness of $P$, simple formulae are derived for the optimal lot sizes $Q_{p}^{(P, 1)}$ for production and $Q_{r}^{(P, 1)}$ for recovery. Furthermore, a modified formulae $\widetilde{Q}_{r}^{(P, 1)}$ for recovery is proposed, which ensures that $P$ is discrete.

The notations are listed in Table 1. 


\section{INSERT TABLE 1 ABOUT HERE}

\section{Policy $(1, R)$}

Figure 2 shows the stocks of recoverable and serviceable items associated with the $(1, R)$ policy.

\section{INSERT FIGURE 2 ABOUT HERE}

The dotted line is a helpful for determining the average stock of recoverables. It crosses all (solid) recoverable stock line-parts exactly in the middle. It is easy to see that the average stock of recoverables during a 'dotted period' is equal to the average height of the dotted line (equal areas of triangles above and below the dotted line), which is clearly half of the maximum stock of recoverables. Since the same holds outside the dotted periods, it follows that the average stock of recoverables (during an entire production/recovery 'cycle') is half of the maximum stock of recoverables.

Figure 2 also shows that the maximum stock of recoverables is equal to the number of returns during a period with $(1-d / r) Q_{r}+Q_{p}$ demands. So, the maximum stock of recoverables is $f\left((1-d / r) Q_{r}+Q_{p}\right)$, and hence the average stock of recoverables is $\frac{1}{2} f\left((1-d / r) Q_{r}+Q_{p}\right)$. Therefore, the average cost per time unit for holding recoverable items is

$$
C_{1}^{(1, R)}:=h_{r} \frac{1}{2} f\left((1-d / r) Q_{r}+Q_{p}\right) .
$$

Similar to the traditional EOQ analysis, it can easily be shown that the average costs per time unit for ordering and for holding serviceable items is

$$
C_{2}^{(1, R)}:=\frac{K_{p} d}{Q_{p}}+h_{s} \frac{1}{2}(1-d / p) Q_{p}
$$

during production periods and

$$
C_{3}^{(1, R)}:=\frac{K_{r} d}{Q_{r}}+h_{s} \frac{1}{2}(1-d / r) Q_{r}
$$

during recovery periods.

Since the return fraction is $f$, we get the following cost expression for the total cost per time unit:

$$
\begin{aligned}
& T C^{(1, R)}\left(Q_{p}, Q_{r}\right) \\
= & C_{1}^{(1, R)}+(1-f) C_{2}^{(1, R)}+f C_{3}^{(1, R)} \\
= & \frac{K_{p} d(1-f)}{Q_{p}}+\frac{K_{r} d f}{Q_{r}}+h_{s} \frac{1}{2}\left((1-f)(1-d / p) Q_{p}+f(1-d / r) Q_{r}\right)+h_{r} \frac{1}{2} f\left((1-d / r) Q_{r}+Q_{p}\right) .
\end{aligned}
$$

Note that the total cost only depends on the lot-sizes. This is because $R$ is fully determined by the lot-sizes via the relation

$$
R Q_{R}(1-f)=Q_{p} f
$$

since the production fraction is $(1-f)$ and the recovery fraction is $f$. Since $R$ has to be discrete, this relation restricts the choice of $Q_{p}$ and $Q_{r}$. We will ignore this restriction for deriving the lot-sizing 
formulae. At the end of this section, however, we discuss how the lot sizes resulting from the formulae can easily be modified so that $R$ is discrete.

Differentiating the above cost expression with respect to $Q_{p}$ and $Q_{r}$ and setting the derivatives to zero gives

$$
-\frac{K_{p} d(1-f)}{Q_{p}^{2}}+h_{s} \frac{1}{2}(1-f)(1-d / p)+h_{r} \frac{1}{2} f=0
$$

and

$$
-\frac{K_{r} d f}{Q_{r}^{2}}+h_{s} \frac{1}{2} f(1-d / r)+h_{r} \frac{1}{2} f(1-d / r) Q_{r}=0,
$$

respectively. So, the optimal lot-sizes are

$$
Q_{p}^{(1, R)}=\sqrt{\frac{2 K_{p} d(1-f)}{h_{s}(1-f)(1-d / p)+h_{r} f}} \quad \text { and } \quad Q_{r}^{(1, R)}=\sqrt{\frac{2 K_{r} d}{\left(h_{s}+h_{r}\right)(1-d / r)}} .
$$

We remark that the lot-size formulae derived by Nahmias \& Rivera (1979) and Schrady (1967) are special cases of the above formulae with $p=r=\infty$ and $p=\infty$, respectively.

Using (2), it follows that the value for $R$ corresponding with $Q_{p}^{(1, R)}$ and $Q_{r}^{(1, R)}$ is

$$
R^{(1, R)}:=\frac{Q_{p}^{(1, R)} f}{Q_{r}^{(1, R)}(1-f)} .
$$

As discussed above, this value generally is not discrete and therefore $Q_{p}^{(1, R)}$ and $Q_{r}^{(1, R)}$ can not be implemented. However, using (2), it is easy to modify $Q_{p}^{(1, R)}$ and/or $Q_{r}^{(1, R)}$ so that the corresponding $R$ is discrete. We propose to modify $Q_{p}^{(1, R)}$ only, since the number of production lots is smaller than or equal to the number of recovery lots for $(1, R)$ policies. We define the modified production lot size as

$$
\widetilde{Q}_{p}^{(1, R)}:=\frac{\widetilde{R}^{(1, R)} Q_{r}^{(1, R)}(1-f)}{f}
$$

where

$$
\widetilde{R}^{(1, R)}:=\max \left\{1,\left[R^{(1, R)}\right]\right\}
$$

is the positive integer nearest to $R^{(1, R)}$.

\section{Policy $(P, 1)$}

Figure 3 shows the stocks of recoverable and serviceable items associated with the $(P, 1)$ policy.

\section{INSERT FIGURE 3 ABOUT HERE}

Using that figure, it is easy to see that the average stock of recoverables is $\frac{1}{2}(1-f d / r) Q_{r}$. Similar to the analysis of the previous section, it follows that the total cost per time unit is

$$
T C^{(P, 1)}\left(Q_{p}, Q_{r}\right)=\frac{K_{p} d(1-f)}{Q_{p}}+\frac{K_{r} d f}{Q_{r}}+h_{s} \frac{1}{2}\left((1-f)(1-d / p) Q_{p}+f(1-d / r) Q_{r}\right)+h_{r} \frac{1}{2}(1-f d / r) Q_{r} .
$$


Note, as in the previous section, that the total cost only depends on the lot-sizes. This is because $P$ is fully determined by the lot-sizes via the relation

$$
Q_{R}(1-f)=P Q_{p} f
$$

Since $P$ has to be discrete, this relation restricts the choice of $Q_{p}$ and $Q_{r}$. As in the previous section, we will ignore this restriction for deriving the lot-sizing formulae. At the end of this section, however, we discuss how the lot sizes resulting from the formulae can easily be modified so that $P$ is discrete.

Differentiating the cost expression with respect to $Q_{p}$ and $Q_{r}$ and setting the derivatives to zero gives

$$
-\frac{K_{p} d(1-f)}{Q_{p}^{2}}+h_{s} \frac{1}{2}(1-f)(1-d / p)=0
$$

and

$$
-\frac{K_{r} d f}{Q_{r}^{2}}+h_{s} \frac{1}{2} f(1-d / r) Q_{r}+h_{r} \frac{1}{2}(1-f d / r)=0,
$$

respectively. So, the optimal lot-sizes are

$$
Q_{p}^{(P, 1)}=\sqrt{\frac{2 K_{p} d(1-f)}{h_{s}(1-f)(1-d / p)}} \quad \text { and } \quad Q_{r}^{(P, 1)}=\sqrt{\frac{2 K_{r} d f}{h_{s} f(1-d / r)+h_{r}(1-f d / r)}} .
$$

We remark that the lot-size formulae derived by Koh et al. (2002) (for the $(P, 1)$ policy if $p>$ $d, r>d)$ are special cases of the above formulae with $p=\infty$.

Using (8), it follows that the value for $P$ corresponding with $Q_{p}^{(P, 1)}$ and $Q_{r}^{(P, 1)}$ is

$$
P^{(P, 1)}:=\frac{Q_{r}^{(P, 1)}(1-f)}{Q_{p}^{(P, 1)} f} .
$$

As discussed above, this value generally is not discrete and therefore $Q_{p}^{(P, 1)}$ and $Q_{r}^{(P, 1)}$ can not be implemented. However, using (8), it is easy to modify $Q_{p}^{(P, 1)}$ and/or $Q_{r}^{(P, 1)}$ so that the corresponding $P$ is discrete. We propose to modify $Q_{r}^{(P, 1)}$ only, since the number of recovery lots is smaller than or equal to the number of production lots for $(P, 1)$ policies. We define the modified recovery lot size as

$$
\widetilde{Q}_{r}^{(P, 1)}:=\frac{\widetilde{P}^{(P, 1)} Q_{p}^{(P, 1)} f}{1-f},
$$

where

$$
\widetilde{P}^{(P, 1)}:=\max \left\{1,\left[P^{(P, 1)}\right]\right\}
$$

is the positive integer nearest to $P^{(P, 1)}$.

\section{Example}

In this section, we illustrate the use of the derived formulae for a specific example. The model parameters are given in Table 2. 


\section{INSERT TABLE 2 ABOUT HERE}

First, we consider $(1, R)$ policies. Using (3) and (4) we get: $Q_{p}^{(1, R)}=50.0, Q_{r}^{(1, R)}=35.4$, and $R^{(1, R)}=5.7$. The corresponding total cost, determined using (1), is 386.3. However, this solution can not be implemented since $R^{(1, R)}$ is not integer. Following (5) and (6), we therefore round $R^{(1, R)}$ to $\widetilde{R}^{(1, R)}=6$ and modify the production lot size to $\widetilde{Q}_{p}^{(1, R)}=53.0$. The corresponding total cost is 386.6 .

Next, we consider $(P, 1)$ policies. Using $(9)$ and $(10)$ we get: $Q_{p}^{(P, 1)}=70.7, Q_{r}^{(P, 1)}=34.3$, and $P^{(P, 1)}=0.1$. However, this solution can not be implemented since $P^{(P, 1)}$ is not integer. Following (11) and (12), we therefore modify $P^{(P, 1)}$ to the nearest positive integer $\widetilde{P}^{(P, 1)}=1$ and the recovery lot size to $\widetilde{Q}_{r}^{(P, 1)}=8.6$. The corresponding total cost is 706.6 .

Since the modified optimal $(1, R)$ policy has much lower cost, it is preferable. This is easily explained, since (i) $f=0.8$ and hence 4 items are recovered for every item that is produced, and (ii) the set-up cost for production is four times higher than the set-up cost for recovery. Indeed, it was obvious beforehand that $(1, R)$ policies are preferable for this case, but we also considered $(P, 1)$ policies for completeness.

We end this example with an small sensitivity study. In practical situations, there may be uncertainty about some of the model parameters, e.g. about the demand rate. Sensitivity analysis is a useful tool in such situations. Since we derived simple formulae for all parameters of the (modified) lot sizing policies, a sensitivity analysis is easy to perform (in any spreadsheet software package). The effects of variations in the demand rate on the modified optimal $(1, R)$ policy are presented graphically in Figure 4.

\section{INSERT FIGURE 4 ABOUT HERE}

The main conclusion from Figure 4 is that, in general, both lot sizes as well as the total cost are increasing in the demand rate. The only exception is the drop in the modified production lot size when the demand rate increases from 1100 to 1200 . This is caused by the change in $\widetilde{R}^{(1, R)}$ from 6 (for demand rates 100 to 1100) to 5 (for demand rates 1200 to 1500). Indeed, the unmodified production lot size $Q_{p}^{(1, R)}$ is strictly increasing in the demand rate.

\section{Conclusion and limitation}

We derived square-root formulae that determine the optimal production and recovery lot-sizes for two classes of policies: $(1, R)$ and $(P, 1)$. Moreover, we proposed simple modifications of resulting lot sizes that ensure discreteness of $R$ or $P$. These results are quite general, since they are valid for finite and infinite production rates as well as finite and infinite recovery rates. Furthermore, they are easy to apply in practice due to their simple form and due to the simple structure of the policies.

A limitation of the considered policies is that they seem too rigid for cases with high variations in the demand rate and in the return fraction. In such cases, it is better to use a policy that allows variations in the number of production or recovery lots per cycle. One reasonable policy is as follows: if the stock drops to 0 , place a recovery order of size $Q_{r}$ if enough recoverable items are available, and place a production order of size $Q_{p}$ otherwise. For such a policy, the formulae that we presented can still be used to as approximations for the optimal lot-sizes. See also Teunter (2002). 


\section{Acknowledgements:}

The research of Dr. Ruud H. Teunter has been made possible by a fellowship of the Royal Netherlands Academy of Arts and Sciences.

The research presented in this paper is part of the research on re-use in the context of the EU sponsored TMR project REVersed LOGistics (ERB 4061 PL 97-5650) in which take part the Otto-von-Guericke Universitaet Magdeburg (D), the Erasmus University Rotterdam (NL), the Eindhoven University of Technology (NL), INSEAD (F), the Aristoteles University of Thessaloniki (GR), and the University of Piraeus (GR).

\section{A Sub-optimality of $(1, R)$ policies in Koh et al. (2002)}

In this appendix, we compare the $(1, R)$ lot sizing policies proposed by Koh et al. $(2002)$ to the $(1, R)$ lot sizing policies proposed by Nahmias \& Rivera (1979) for systems with an infinite production rate and a finite recovery rate. For ease of notation, these will be referred to as K-policies and N-policies, respectively. We further use the notations in Table 1.

We assume that the holding cost rate for serviceable items is larger than that for recoverable items. This assumption usually holds in practice, since recovery adds value to a returned item. We show that under the assumption, the total cost for a K-policy is larger than that for an N-policy with the same number of recovery lots per production lot $R$, and with the same lot sizes $Q_{p}$ and $Q_{r}$.

A K-policy starts a recovery lot of size $Q_{r}$ as soon as the stock of recoverable items reaches level $(1-r / p) Q_{r}$. The recovery lot is complete after $Q_{r} / p$ time units, at which moment the stock of recoverable items drop to $(1-r / p) Q_{r}-\left(Q_{r} / p\right)(p-r)=0$. A production lot of size $Q_{m}$ is started as soon as the stock of serviceable items drops to 0 . Since there is an infinite production rate, production lots are ready immediately.

An N-policy is a special case, for an infinite production rate, of the $(1, R)$ lot sizing policies studied in this paper (see Section 3). It differs from a K-policy in only one aspect: recovery lots are postponed until the stock of serviceable items drops to 0, i.e. until they are needed.

Figure 5 compares, for a specific example, the stocks of recoverable and serviceable items for the K-policy and the N-policy with $Q_{p}=120, Q_{r}=40$, and $R=3$.

\section{INSERT FIGURE 5 ABOUT HERE}

As Figure 5 clearly shows, both policies have the same cycle time. Let us define a cycle as the time period between two successive times at which a production lot is ordered. Figure 5 shows that just before a cycle starts, both policies have a zero stock of serviceable items and the same stock of recoverable items. Since both policies face the same demand rate and return fraction, this implies that both policies have the same total (recoverable and serviceable) stock at any time during a cycle, and hence the same average total stock. But, contrary to a K-policy, an N-policy postpones all recovery lots until the stock of serviceable items drops to 0. Clearly, this reduces the average stock of serviceable items. And since the average total stock is unchanged, it increases the average stock of recoverable items by the same amount. This results in a cost reduction if the holding cost rate for serviceable items is larger than that for recoverable items, as was assumed. 


\section{References}

Koh, S.-G., Hwang, H., Sohn, K.-I., \& Ko, C.-S. (2002). An optimal ordering and recovery policy for reusable items. Computers and Industrial Engineering, 43, 59-73.

Mabini, M.C., Pintelon, L.M., \& Gelders, L.F. (1998). EOQ type formulations for controlling repairable inventories. International Journal of Production Economics, 54, 173-192.

Nahmias, N., \& Rivera, H. (1979). A deterministic model for a repairable item inventory system with a finite repair rate. International Journal of Production Research, 17 (3), 215-221.

Richter, K. (1996a). The EOQ and waste disposal model with variable setup numbers. European Journal of Operational Research, 95, 313-324.

Richter, K. (1996b). The extended EOQ repair and waste disposal model. International Journal of Production Economics, 45 (1-3), 443-448.

Schrady, D.A. (1967). A deterministic inventory model for repairable items. Naval Research Logistics Quarterly, 14, 391-398.

Teunter, R.H. (2001). Economic ordering quantities for recoverable item inventory systems. Naval Research Logistics, 48, 484-495.

Teunter, R.H. (2002). Economic Ordering Quantities for stochastic discounted cost inventory systems with remanufacturing. International Journal of Logistics, 5 (2), 161-175.

Teunter, R.H., \& Vlachos, D. (2002). On the necessity of a disposal option for returned products that can be remanufactured. International Journal of Production economics, 75, 257-266. 


\begin{tabular}{ll}
\hline$d$ & demand rate \\
$f$ & return fraction (return rate $f d)$ \\
$p$ & production rate \\
$r$ & recovery rate \\
$K_{p}$ & ordering (setup) cost per production lot \\
$K_{r}$ & ordering (setup) cost per recovery lot \\
$h_{r}$ & holding cost per recoverable item per time unit \\
$h_{s}$ & holding cost per serviceable item per time unit \\
$Q_{p}$ & production lot-size \\
$Q_{r}$ & recovery lot-size \\
\hline$T C^{(1, R)}\left(Q_{p}, Q_{r}\right)$ & total cost for $(1, R)$ policy with lot sizes $Q_{p}$ and $Q_{r}$ \\
$Q_{p}^{(1, R)}$ & optimal production lot-size for $(1, R)$ policy \\
$Q_{r}^{(1, R)}$ & optimal recovery lot-size for $(1, R)$ policy \\
$R^{(1, R)}$ & value for $R$ corresponding with $Q_{p}^{(1, R)}$ and $Q_{r}^{(1, R)}$ \\
$\widetilde{Q}_{p}^{(1, R)}$ & modified optimal production lot-size for $(1, R)$ policy \\
$\widetilde{R}^{(1, R)}$ & discrete value for $R$ corresponding with $\widetilde{Q}_{p}^{(1, R)}$ and $Q_{r}^{(1, R)}$ \\
\hline$T C^{(P, 1)}\left(Q_{p}, Q_{r}\right)$ & total cost for $(P, 1)$ policy with lot sizes $Q_{p}$ and $Q_{r}$ \\
$Q_{p}^{(P, 1)}$ & optimal production lot-size for $(P, 1)$ policy \\
$Q_{r}^{(P, 1)}$ & optimal recovery lot-size for $(P, 1)$ policy \\
$P^{(P, 1)}$ & value for $P$ corresponding with $Q_{p}^{(P, 1)}$ and $Q_{r}^{(P, 1)}$ \\
$\widetilde{Q}_{r}^{(P, 1)}$ & modified optimal recovery lot-size for $(P, 1)$ policy \\
$\widetilde{P}^{(P, 1)}$ & discrete value for $P$ corresponding with $Q_{p}^{(P, 1)}$ and $\widetilde{Q}_{r}^{(P, 1)}$ \\
\hline
\end{tabular}

Table 1: Notations. 


\begin{tabular}{ccccccccc}
\hline Model parameter & $d$ & $f$ & $p$ & $r$ & $K_{p}$ & $K_{r}$ & $h_{r}$ & $h_{s}$ \\
Value & 1000 & 0.8 & 5000 & 3000 & 20 & 5 & 10 & 2 \\
\hline
\end{tabular}

Table 2: Model parameter settings for the example. 


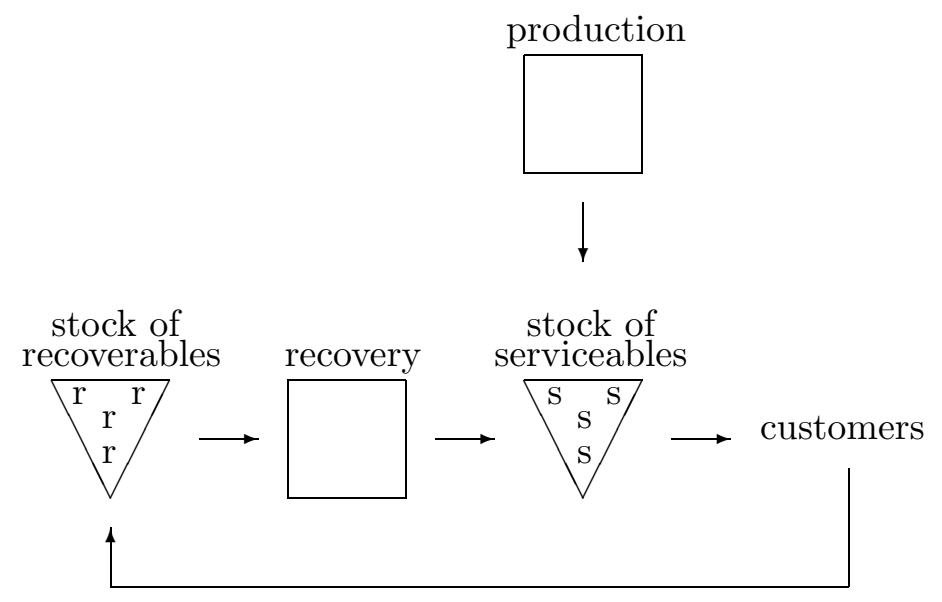

Figure 1: Inventory system with product recovery. 


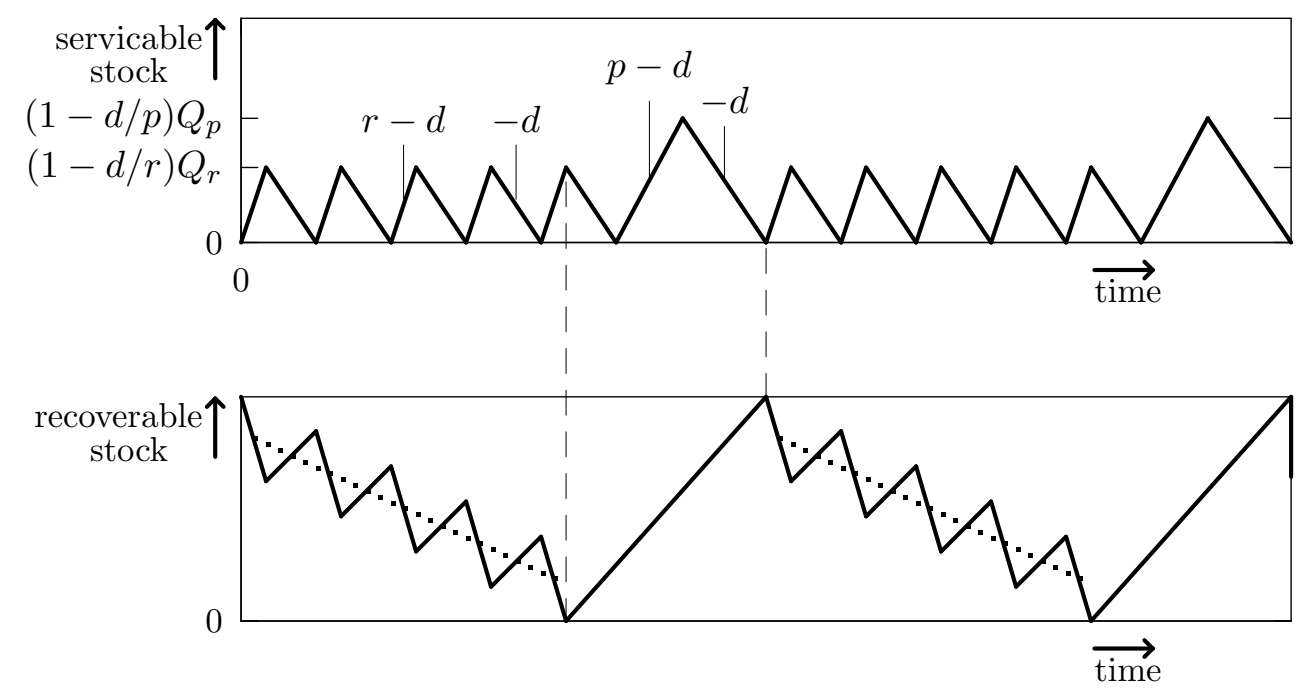

Figure 2: Serviceable and recoverable stock corresponding to the $(1, R)$ policy ( $R=5$ for this example) during two cycles. The dotted line is a 'help-line' for determining the average stock of recoverables (see text). 


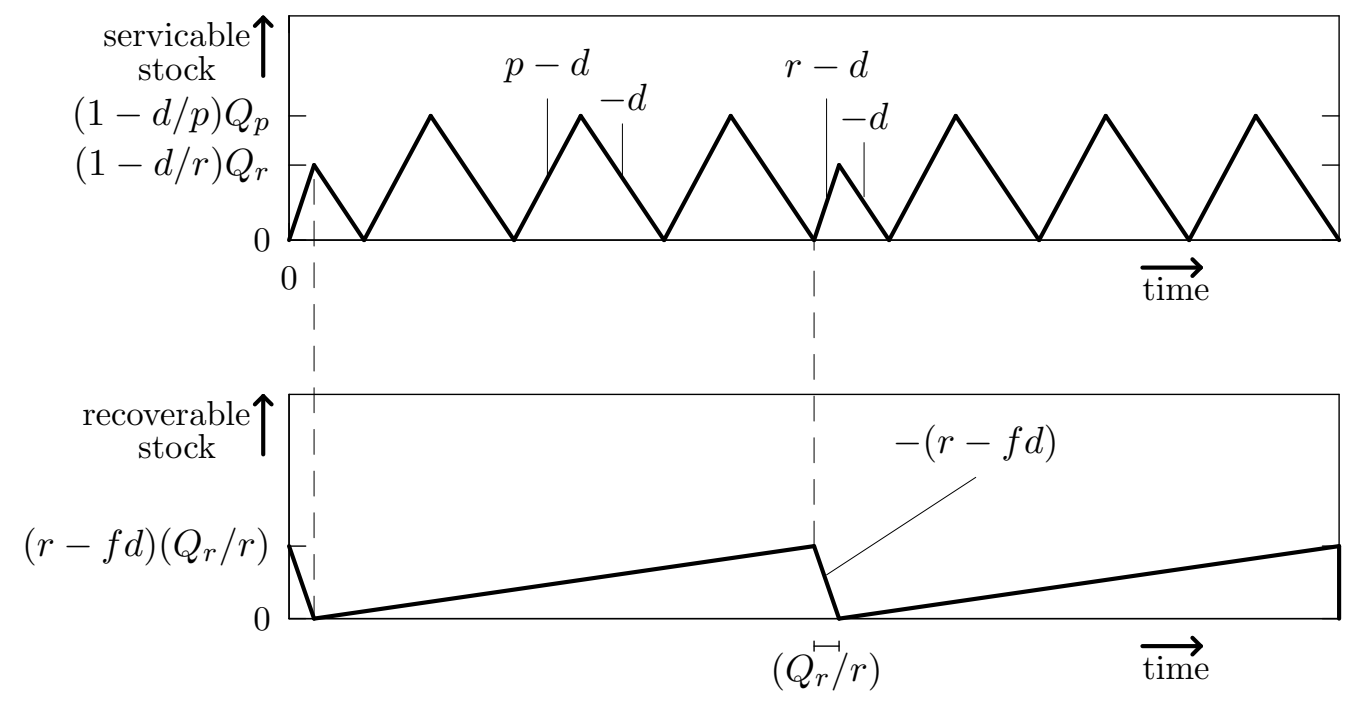

Figure 3: Serviceable and recoverable stock corresponding to the $(P, 1)$ policy $(P=3$ for this example) during two cycles. 


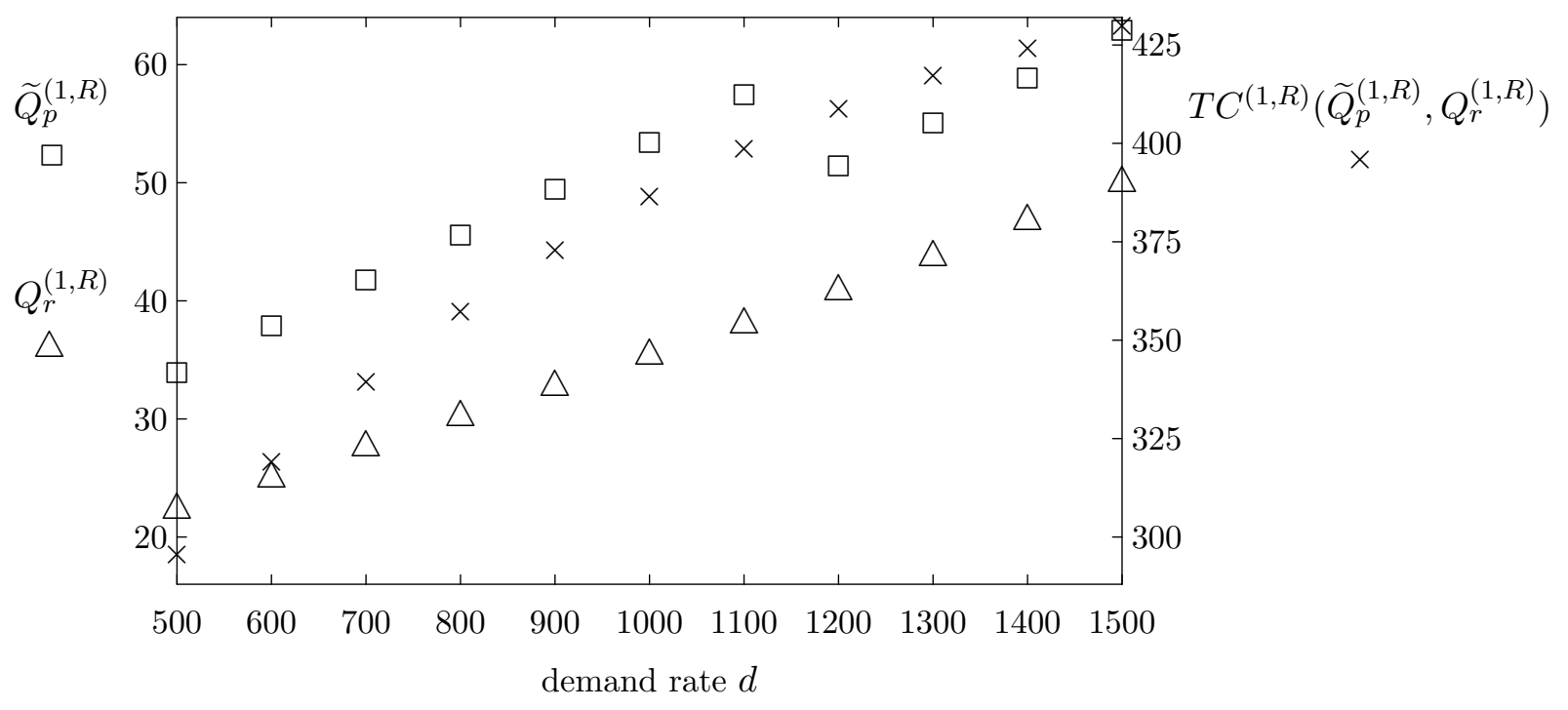

Figure 4: Effects of variations (from the parameter settings in Table 2) in $d$ on $\widetilde{Q}_{p}^{(1, R)}, Q_{r}^{(1, R)}$, and $T C^{(1, R)}\left(\widetilde{Q}_{p}^{(1, R)}, Q_{r}^{(1, R)}\right)$. 

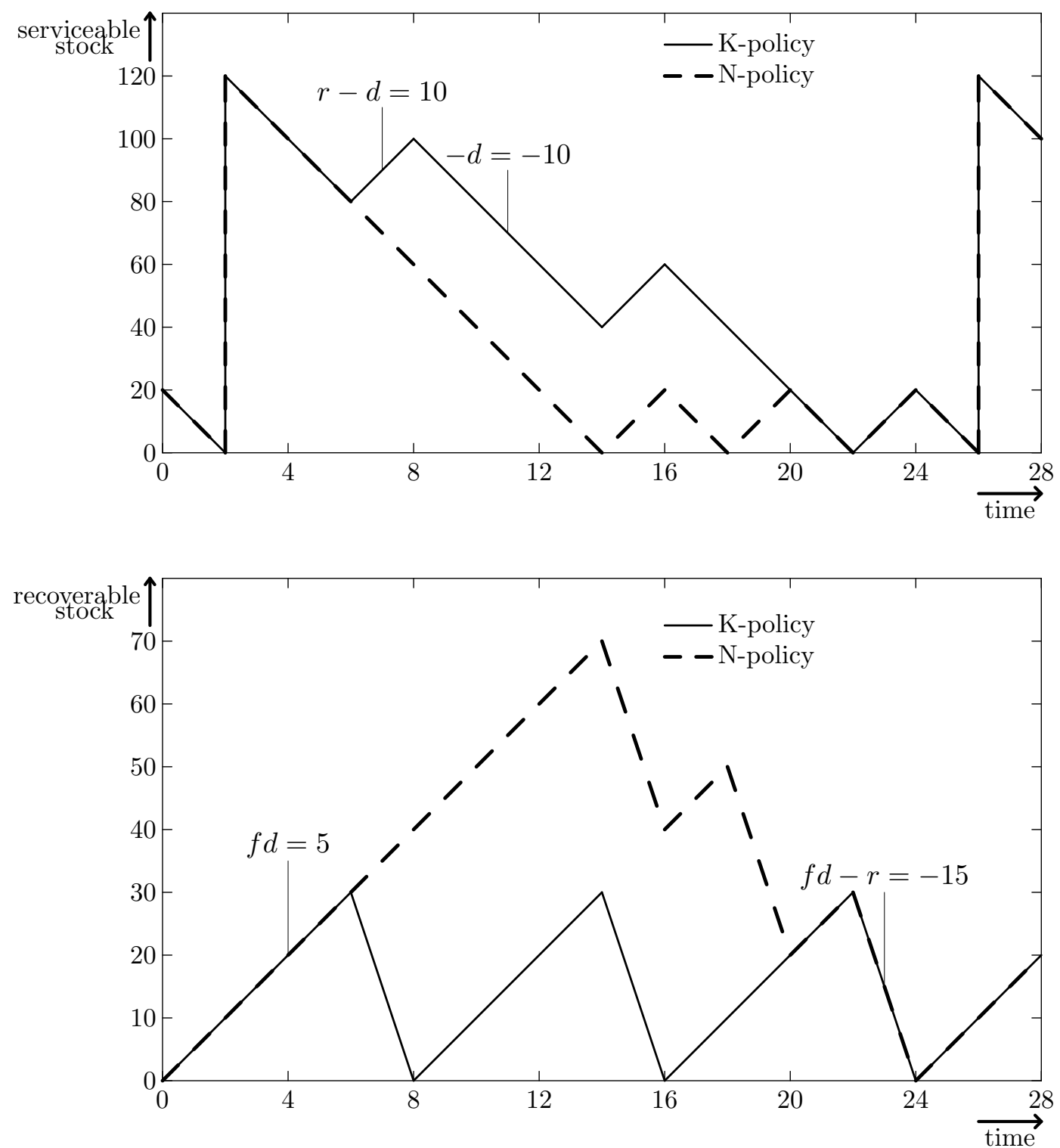

Figure 5: Comparison of stock levels between the K-policy (Koh. et al., 2002) and the N-policy (Nahmias \& Rivera, 1979), both with production lot size $Q_{p}=120$, recovery lot size $Q_{r}=40$, and $R=3$ recovery lots per production lot (demand rate $d=5$, return fraction $f=0.5$, recovery rate $r=20$, production rate $p=\infty$ ). 